\title{
Blockade of the Mineralocorticoid Receptor in Healthy Men: Effects on Experimentally Induced Panic Symptoms, Stress Hormones, and Cognition
}

\author{
Christian Otte*,', Steffen Moritz', Alexander Yassouridis², Maike Koop', Ana Maria Madrischewski', \\ Klaus Wiedemann' and Michael Kellner' \\ 'Department of Psychiatry and Psychotherapy, University Hospital Hamburg-Eppendorf, Hamburg, Germany; ${ }^{2}$ Department of Biostatistics, \\ Max Planck Institute of Psychiatry, Munich, Germany
}

\begin{abstract}
Animal studies have shown that blockade of central mineralocorticoid receptors (MR) has anxiolytic effects and impairs several aspects of cognitive function. No study to date assessed the effects of MR blockade on anxiety and cognitive function in humans. In the present study, 16 healthy young men were treated either with placebo or with 300 mg spironolactone, a MR-antagonist, at I I00, I330, and I630 hours in a balanced cross-over design with the two study conditions being I week apart. At I 500 hours, the panic symptoms provoking compound cholecystokinin-tetrapeptide (CCK-4) was administered i.v. on both occasions and panic symptoms were assessed. We measured plasma ACTH and cortisol between 1300 and 1900 hours and assessed cognitive function between 1800 and 1900 hours. CCK-4 elicited panic symptoms and increased ACTH and cortisol secretion in both conditions. Intensity of panic symptoms after CCK-4 was not different between spironolactone and placebo. Spironolactone significantly impaired selective attention and delayed recall of visuospatial memory, and diminished set shifting/mental flexibility on a trend level. Pretreatment with spironolactone led to higher baseline cortisol levels compared to placebo whereas no differences in stimulated cortisol, baseline ACTH, and stimulated ACTH emerged. Blockade of MR with spironolactone increases baseline cortisol secretion and impairs cognitive function but has no effect on experimentally induced panic symptoms in humans, for the study design and dosage of spironolactone used. The domains of cognitive function that are impaired after blockade of MR in men, that is, selective attention, visuospatial memory, and mental flexibility/set shifting appear to be remarkably similar to those described in animal studies.
\end{abstract}

Neuropsychopharmacology (2007) 32, 232-238. doi:I0.1038/sj.npp. I301217; published online II October 2006

Keywords: cortisol; HPA axis; mineralocorticoid receptor; cholecystokinin-tetrapeptide; panic; memory

\section{INTRODUCTION}

Alterations of the hypothalamic-pituitary-adrenal (HPA) axis leading to cortisol dysregulation are involved in mood and anxiety disorders. Cortisol exerts its effects via two different receptors, the mineralocorticoid receptor (MR) and the glucocorticoid receptor (GR). MR are predominantly expressed in the hippocampus. MR bind glucocorticoids with a 10-fold higher affinity than GR, which are widely distributed in brain and periphery. Both GR and MR are involved in anxiety and cognitive function (de Kloet et al, 2005).

\footnotetext{
*Correspondence: Dr C Otte, Department of Psychiatry and Psychotherapy, University Hospital Hamburg-Eppendorf, Martinistrasse 52, 20246 Hamburg, Germany, Tel: + 494042803 4677, Fax: + 4940 42803 346I, E-mail: otte@uke.uni-hamburg.de

Received 10 April 2006; revised and accepted I June 2006

Online publication: 7 September 2006 at http://www.acnp.org/ citations/Npp090706060229/default.pdf
}

Animal studies demonstrated an increase in hippocampal MR density after psychological stress (Gesing et al, 2001; Ladd et al, 2004; Muller et al, 2003; Sandi and Touyarotb, 2006). Furthermore, blockade of MR seems to be anxiolytic in animals (Bitran et al, 1998; Korte et al, 1995; Smythe et al, 1997). However, no studies examined the effects of MR blockade on anxiety and panic in humans.

With regard to cognitive function, animal studies have demonstrated that MR are involved in interpretation of novel information (Berger et al, 2006; Oitzl and de Kloet, 1992; Sandi and Rose, 1994), memory retrieval (Conrad et al, 1997; Yau et al, 1995), and visuospatial learning (Douma et al, 1998; Yau et al, 1999; Yau et al, 1995). In healthy humans, only one study examined the interaction of sleep and MR blockade on consolidation of declarative memory and failed to find an effect of MR blockade (Plihal and Born, 1999). However, in patients with Addison's disease it was recently shown that MR are needed for encoding learned material (Tytherleigh et al, 2004). Furthermore, MR function is altered in major depression 
that is associated with cognitive deficits (Buckley, 2006; Holsboer, 2000; Young et al, 2003).

The impact of MR on HPA activity in humans is well documented. Most studies (Deuschle et al, 1998; Heuser et al, 2000a, b; Kellner et al, 2002a, b; Young et al, 1998) have shown elevated basal plasma cortisol concentrations after administration of spironolactone, a MR antagonist. Also, after CRH stimulation (Arvat et al, 2001; Kellner et al, $2002 a$, b) as well as in a combined dexamethasone suppression/CRH stimulation test (Heuser et al, 2000a, b) and during exercise (Wellhoener et al, 2004) significant elevations of plasma cortisol after prior anti-MR treatment have been reported.

To our knowledge, no study examined the impact of MR blockade on HPA activity during experimentally induced panic symptoms. Therefore, we examined the effects of spironolactone on HPA axis activity, cognitive function, and panic symptoms after cholecystokinin-tetrapeptide (CCK-4). Intravenous injection of CCK-4 is an established model to experimentally elicit short-lived panic-like anxiety symptoms not only in patients with panic disorder, but (using higher dosages) also in healthy volunteers (Bradwejn et al, 1995; Kellner et al, 2002a, b; Wiedemann et al, 2001). In addition to its panicogenic effects, CCK-4 activates pituitary-adrenocortical hormone release and sympathetic activity (Wiedemann et al, 2001).

We hypothesized that 1) MR blockade reduces anxiety after CCK-4, 2) MR blockade impairs cognitive function, and 3) MR blockade leads to increased basal and stimulated ACTH and cortisol levels.

\section{MATERIALS AND METHODS}

\section{Subjects}

Sixteen healthy normal-weighted men (mean age \pm SD $25.1 \pm 2.6$ years, mean body mass index $23.3 \pm 2.3 \mathrm{~kg} / \mathrm{m}^{2}$ ) were studied. Subjects were community volunteers in excellent physical general health as determined by an interview, a physical examination, routine laboratory tests, and a urine drug screening. Diagnosis of a psychiatric axis I illness was excluded by the MINI-Interview (Sheehan et al, 1998). The study was approved by the Ethics Committee of the General Medical Council of Hamburg and written informed consent was obtained from all subjects.

\section{Procedure}

Each participant in this cross-over study was examined on two occasions with 1 week between the respective study days (Figure 1). The participants arrived at 1100 hours, an intravenous catheter was inserted at 1300 hours and volunteers were restricted from smoking, eating, ad libitum drinking and remained sedentary in bed without sleeping until 1900 hours. Between sampling the tubing system was kept patent by a $0.9 \%$ saline infusion at a rate of $50 \mathrm{ml} / \mathrm{h}$.

In a randomized, balanced order, the subjects orally received either $300 \mathrm{mg}$ spironolactone or placebo at 1100 and 1330 hours. Blood was drawn in regular intervals (see Figure 1). At 1500 hours, participants received $50 \mu \mathrm{g}$ CCK-4 (Clinalfa, Läufelingen, Switzerland). The following psychometric assessments were performed at baseline (1430) and at 1505 hours (to determine post hoc the peak of provoked symptoms): The Acute Panic Inventory (API) (Dillon et al, 1987), a DSM-IV panic symptom checklist (Hiller et al, 1993), and two $100 \mathrm{~mm}$ visual analog scales (VAS) for the items 'anxiety' and 'arousal'. Raters were blind with regard to the study condition, that is, were unaware if the participants received spironolactone or placebo.

Ninety minutes after the CCK-challenge, that is, at 1630 hours participants again received $300 \mathrm{mg}$ spironolactone or placebo. Between 1800 and 1900 hours, neuropsychological testing took place.

\section{Neuropsychological Measures}

Auditory verbal learning test (AVLT) (Lezak, 1995): The AVLT is a measure of verbal learning and short-term and long-term verbal memory. The experimenter reads a list of 15 words (list A), which the participant is requested to repeat in loose order. After list A has been presented five times, the subject is asked to reproduce words from a newly presented list (list B). Following this, the subject is instructed to recall the words from list A without renewed presentation. After $30 \mathrm{~min}$, the subject is again asked to repeat the words from list A.

Rivermead behavioral memory test (RBMT) (Wilson et al, 1992): The RBMT is a test battery that assesses diverse aspects of everyday memory, such as remembering a name, prospective memory, short-term and long-term prose recall, and orientation. The tasks have been validated in a number of studies (eg, Perez and Godoy, 1998).

Test $d 2$ (Brickenkamp, 1978): The Test $d 2$ is a letter cancellation test that taps selective attention/concentration. In this task, the subject is instructed to cross out the letter $d$ whenever it is accompanied by two small lines; $d$ 's with more than or less than two lines or any stimuli containing the character $p$ serve as distracters. Subsequent to a practice trial, 14 rows with target and distracter stimuli are presented.

Trail-making test (TMT) (Reitan, 1992): Psychomotor slowness was assessed with the TMT part A. In this task, the subject has to connect encircled numbers in ascending order as quickly as possible. Part B assesses cognitive set

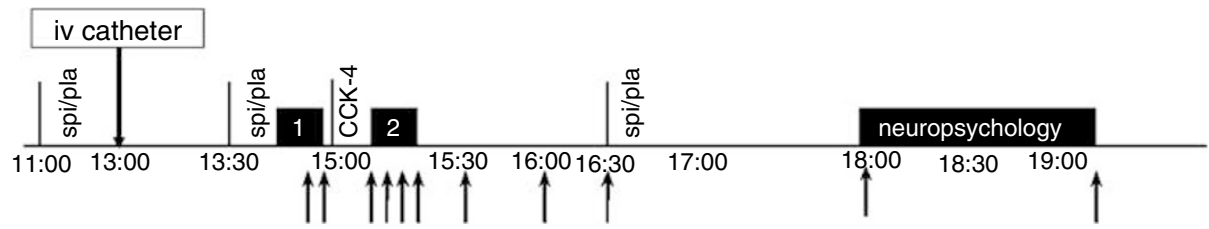

Figure I Timetable of the procedures on each day. I = pre-CCK-4 assessment, 2 = post-CCK-4 assessment, arrows=times of plasma sampling, spi $=$ spironolactone, and pla $=$ placebo 
shifting and requires the alternation between numbers and letters, again in ascending order.

Forward and backward digit span (Tewes, 1991): This task forms part of the Wechsler Adult Intelligence Scale (WAIS). During the forward digit span task, participants are asked to remember a series of digits and repeat them back to the investigator in the same order. During the backward digit span task, however, they are asked to repeat the digits in reverse order. This additional mental activity required during the Backward Digit Span task allows it to be considered much more a task of working memory.

Rey-osterrieth complex figure test (RCFT) and taylor complex figure test (TCFT) (Osterrieth, 1944): These tests measure visuospatial memory. The participant is required to copy a complex figure. Immediately thereafter and $20 \mathrm{~min}$ later the figure has to be re-drawn from memory.

We used parallel versions of the AVLT, RBMT, the digit span test, and the Rey and Taylor figures to control for learning effects. With regard to the TMT and $\mathrm{d} 2$ tests, no parallel versions exist. For these variables, order was included in the statistical analysis as covariates.

\section{Hormone Analysis, Heart Rate, and Blood Pressure}

Each blood sample was placed on ice, plasma was separated, and aliquots stored at $-80^{\circ} \mathrm{C}$ until analysis. Blood pressure and heart rate were registered at blood sampling time points with an automatic device. Plasma concentrations of ACTH and cortisol were determined using commercial radioimmunoassays (ICN Biomedicals, Carson, CA; Nichols Institute, San Juan Capistrano, CA). Inter- and intraassay coefficients of variation for all hormones were below $8 \%$. Detection limits were $0.5 \mathrm{ng} / \mathrm{ml}$ for cortisol and $2 \mathrm{pg} / \mathrm{ml}$ for ACTH.

\section{Statistical Analyses}

Differences between spironolactone and placebo treatment on psychometric, neuropsychological and endocrine parameters were analyzed using multivariate analyses of variance (MANOVA) with repeated measures design. If significant treatment effects were found, univariate $\mathrm{F}$ tests followed to identify the parameters on which these effects were significant. Psychometric data are given as changes between pre-CCK- 4 and post-CCK- 4 ratings, whereas for the endocrine data three curve indicators, namely 'mean location' (mean), 'maximal increase' (delta) and 'area under curve' (AUC) after CCK-4 stimulation (time period from baseline until $1630 \mathrm{~h}$ ) were considered in the analysis of variance. Mean values of pre-CCK-4 hormone concentrations and of psychometric parameters were defined as 'baseline' measures. As a nominal level of significance, $\alpha=0.05$ was accepted. All post hoc tests (univariate F tests and tests with contrasts) were performed at a reduced level of significance (Bonferroni procedure) to keep the type I error less than or equal to 0.05 .

\section{RESULTS}

There were no side effects after spironolactone administration. All participants completed both study days.

\section{CCK-4 Challenge}

Behavioral data. CCK-4 significantly increased scores of panic symptoms as measured by the Acute Panic Inventory and the ICD-Checklist (Table 1). CCK-4 also increased anxiety and arousal as measured by a VAS. However, there were no significant differences between spironolactone and placebo on the increase of panic symptoms, anxiety, or arousal.

Endocrine response, heart rate, and blood pressure. Compared to placebo, spironolactone significantly increased baseline cortisol values at 1445 and 1500 hours before CCK-4 $(P<0.01$, Figure 2$)$. Baseline ACTH values did not differ between placebo and spironolactone (Figure 3). Administration of CCK-4 increased cortisol and ACTH concentrations (Figure 2). In MANOVA, there was a significant effect of treatment for the variable 'mean location' $(\mathrm{F}=13.4, P<0.01)$ reflecting higher mean cortisol but not ACTH levels after spironolactone throughout the procedure. However, there was no significant effect of treatment for the variables 'delta' and 'AUC 'indicating that the increase of cortisol and ACTH after CCK-4 was not different between spironolactone and placebo (Figure 2).

Heart rate and blood pressure at baseline did not differ between placebo and spironolactone. Further, CCK-4 did not increase heart rate and blood pressure and both variables did not differ between placebo and spironolactone after CCK-4 (data not shown).

\section{Neuropsychology}

Compared to placebo, blockade of MR with spironolactone significantly impaired selective attention as measured

Table I The Effect of CCK-4 on Scores of the Acute Panic Inventory (API), ICD-Checklist (ICDL), and Visual Analog Scale for 'Anxiety' and 'Arousal' after Pre-Treatment with Spironolactone vs Placebo

\begin{tabular}{|c|c|c|c|c|c|}
\hline \multirow[b]{2}{*}{ Measures } & \multicolumn{2}{|c|}{ Placebo } & \multicolumn{3}{|c|}{ Spironolactone } \\
\hline & Pre-CCK-4 Mean (SD) & Post-CCK-4 Mean (SD) & Pre-CCK-4 Mean (SD) & Post-CCK-4 Mean (SD) & F, P-value \\
\hline ICDL & $0 \pm 0$ & $6.3 \pm 1.7$ & $0.2 \pm 0.5$ & $6 \pm 2.5$ & $0.46,0.51$ \\
\hline VAS 'anxiety' & $5.0 \pm 5.2$ & $39.1 \pm 26.8$ & $5.9 \pm 6.1$ & $35.9 \pm 25.1$ & $0.27,0.61$ \\
\hline
\end{tabular}


by the d2-test (Table 2). Spironolactone also significantly attenuated delayed recall of spatial/non-verbal memory as measured by the Rey-/Taylor figures. On a trend level, blockade of MR led to a diminished ability of cognitive set shifting as measured by the Trail-Making-Test B. No differences between spironolactone and placebo emerged in the Trail-Making-Test A, the RBMT, the AVLT, and the Digit Span test.

Before (1800 hours) and after (1900 hours) neuropsychological testing, cortisol levels were significantly higher in the spironolactone vs placebo condition (1800 hours: mean cortisol after spironolactone $170.6 \pm 60.6 v s$ placebo $77.8 \pm 21.6 \mathrm{ng} / \mathrm{ml}, P<0.01,1900$ hours: mean cortisol after spironolactone $175.4 \pm 64.9$ vs placebo $91.6 \pm 39.8, P<0.01$ ). There were no differences in ACTH after spironolactone

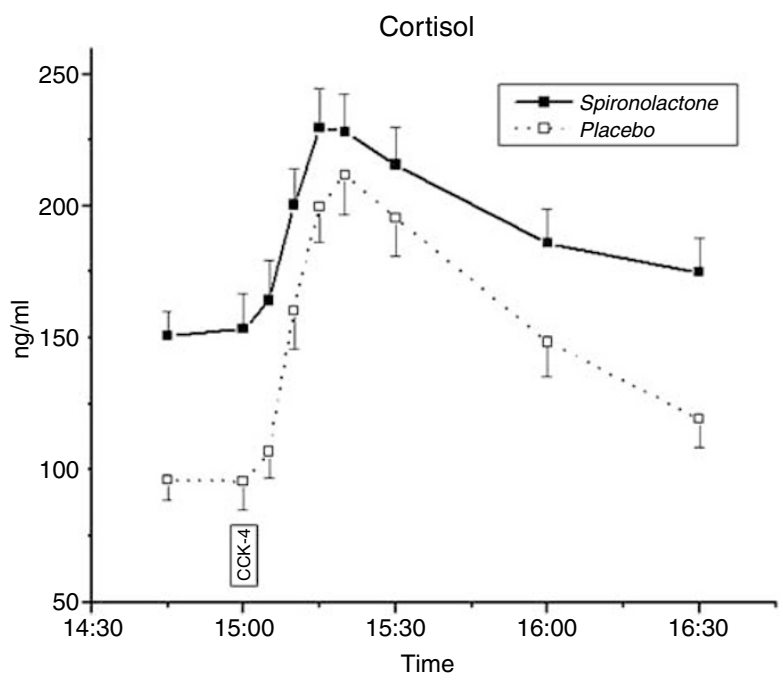

Figure 2 Mean values of cortisol after pretreatment with spironolactone vs placebo. Values are means \pm SEM. and placebo before and after neuropsychological testing. Neither after spironolactone nor after placebo, significant correlations between cortisol or ACTH levels with variables of neuropsychological functioning emerged.

\section{DISCUSSION}

The main result of this study is that blockade of MR with spironolactone in healthy men impairs several aspects of cognition, that is selective attention, visuospatial memory, and set shifting/mental flexibility. Furthermore, spironolactone led to increased baseline cortisol but did not affect the increase of cortisol after CCK-4. Spironolactone did not affect symptoms of panic, anxiety and arousal after CCK-4.

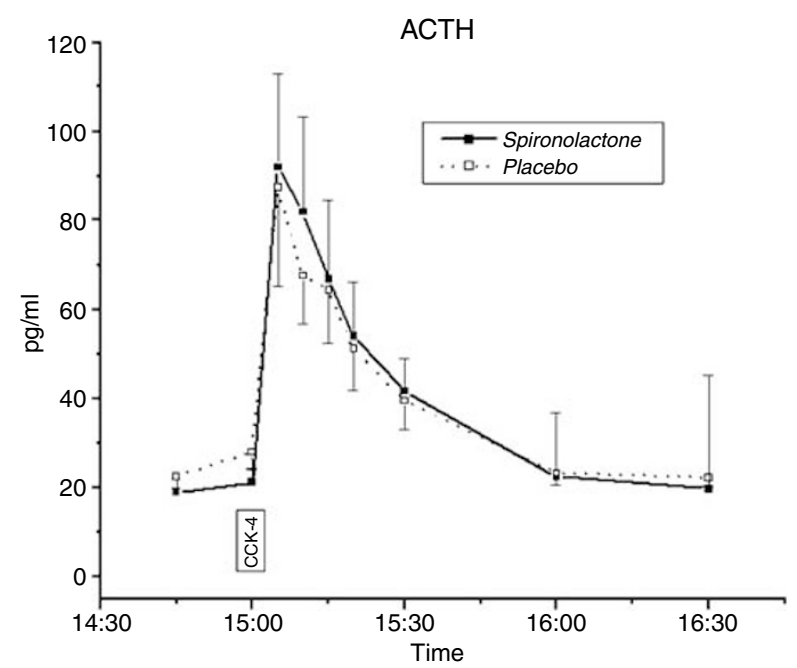

Figure 3 Mean values of ACTH after pretreatment with spironolactone vs placebo. Values are means \pm SEM.

Table 2 The Effect of Spironolactone vs Placebo on Different Domains of Cognitive Functioning

\begin{tabular}{|c|c|c|c|c|c|}
\hline \multirow{2}{*}{$\begin{array}{l}\text { Measures } \\
\text { Test d } 2\end{array}$} & \multicolumn{2}{|c|}{ Placebo, Mean (SD) } & \multicolumn{2}{|c|}{ Spironolactone, Mean (SD) } & \multirow{2}{*}{$\begin{array}{c}\text { F, } P \text {-Value } \\
9.6,<0.01\end{array}$} \\
\hline & 83.0 & $(23.5)$ & 63.2 & $(22.4)$ & \\
\hline TMT A (s) & 20.4 & $(5.7)$ & 20.9 & $(5.5)$ & $0.10,0.71$ \\
\hline TMT B (s) & 55.3 & $(17.1)$ & 60.7 & $(14.4)$ & $3.3,0.09$ \\
\hline RBMT** & & & & & $0.79,0.39$ \\
\hline Immediate recall & 12.7 & $(4.0)$ & 13.0 & $(4.1)$ & \\
\hline Rey/Taylor Figure** & & & & & $10.0,<0.01$ \\
\hline Copy & 30.0 & $(3.7)$ & 29.9 & $(4.5)$ & \\
\hline Immediate recall & 24.1 & $(4.1)$ & 22.9 & $(5.5)$ & \\
\hline Delayed recall & 24.2 & $(5.0)$ & 21.2 & $(5.7)$ & \\
\hline \multicolumn{6}{|l|}{ Digit Span } \\
\hline
\end{tabular}

TMT, Trail Making Test; RBMT, Rivermead Behavioral Memory Test; AVLT, Auditory Verbal Learning Test.

*Indicates $F$ and $P$-values for treatment by time interaction.

The bold values are the $F$ and $P$-values. The $P$-values equal the significance. 
To our knowledge, this is the first study in humans demonstrating that blockade of MR impairs certain domains of cognitive function, that is, selective attention, visuospatial memory, and mental flexibility/set shifting. The domains of cognitive function that are impaired after blockade of MR in men appear to be remarkably similar to those described in animal studies. In animals, spironolactone impaired interpretation of novel information and processes of evaluation and response selection (Oitzl and de Kloet, 1992; Sandi and Rose, 1994). Furthermore, mutant mice with an inactivated MR gene in the forebrain showed impaired learning and working memory owing to behavioral perseverance and stereotypy (Berger et al, 2006). Both animal studies are consistent with our findings of diminished selective attention and mental flexibility after MR blockade. Furthermore, memory retrieval (Conrad et al, 1997; Yau et al, 1995), and visuospatial learning (Douma et al, 1998; Yau et al, 1999; Yau et al, 1995) was impaired after MR blockade in animals. This is consistent with our findings of attenuated delayed recall of the Rey-/Taylor figures that measure visuospatial memory. Future studies in different groups (eg, in women, in the elderly, in clinical populations) should further elucidate if MR are critically involved in sensory integration of spatial environmental clues.

It has been shown earlier in animal studies that antidepressants upregulate MR in the hippocampus and improve spatial memory (Yau et al, 2002; Yau et al, 1995). Interestingly, there was a strong correlation between MR expression in the hippocampus and spatial learning in young but not old rats in which antidepressants failed to increase MR expression and also failed to improve spatial learning (Yau et al, 1995). Thus, it is possible that the positive effects of antidepressants on cognitive function in depressed patients are mediated by a rise of hippocampal MR. This is also consistent with findings that the MR antagonist spironolactone hampered antidepressive effects of an antidepressant in humans (Holsboer, 2000) and that substances that upregulate MR enhance the effects of antidepressants (Jahn et al, 2004).

Also consistent with the hypothesis that MR play a major role in cognition are results from animal and human studies examining the effect of aging on MR expression and function (Buckley and Schatzberg, 2005). In rats and dogs it has been shown that MR expression in the hippocampus is reduced in aged animals (Rothuizen et al, 1993; Yau et al, 2002). Consistent with these findings, aged humans showed diminished MR-mediated inhibition on cortisol secretion (Heuser et al, 2000a, b; Otte et al, 2003). Thus, diminished MR expression may contribute to cognitive deficits in aging and depression. Our results, although preliminary, warrant further research on the association between MR and cognitive function in physiological conditions such as aging and pathological conditions such as major depression.

One earlier study in humans examined the interaction between sleep and MR blockade on declarative and spatial memory (Plihal and Born, 1999) and failed to find an effect of MR blockade. However, there are considerable differences between this earlier and our study. First, that study looked at an interaction effect between sleep and MR blockade on memory. Learning took place between 2200 and 2300 hours and participants were awakened after $3 \mathrm{~h}$ of retention sleep and retrieval was tested between 0230 and 0300 hours. Furthermore, a lower dosage of spironolactone (200 mg) compared to our study was given at 0900 and 1700 hours the day before retrieval took place. These differences in study design might have caused the differences in the two studies.

We did not find differences between spironolactone and placebo on any of the measures of panic, anxiety, and tension after CCK-4. Thus, it is unlikely that MR are critically involved in experimentally induced anxiety in humans. However, the mechanism of CCK-4 induced panic has not been established. Preclinical and clinical studies suggest that brainstem CCK-B receptors may mediate the panicogenic effects of CCK-4, possibly through direct or indirect interaction with other neurotransmitter systems (Rehfeld, 2000). Recently, it was shown in animals that MR are crucial in the stress response to a mild, but not moderate, psychological stressor (Pace and Spencer, 2005). It is possible that MR blockade might be relevant for naturally occurring panic attacks or other forms of experimentally-induced anxiety (eg, elicited by psychosocial stress) that are caused by different pathway than CCK-4 induced panic.

Previous animal studies with MR antagonists have consistently shown an anxiolytic effect of MR blockade. However, in one study MR blockade was only anxiolytic in conditioned fear but had no effects in the absence of preexposure to an aversive stimuli (Korte et al, 1995) which could explain the lack of anxiolysis by MR blockade in our study that did not use a fear-conditioning paradigm. Another animal study found a dose-dependant inverted U-shaped curve for the anxiolytic effects of MR blockade (Bitran et al, 1998). Maybe in our study the dosage was too low or too high to elicit an anxiolytic effect in the CCK-4 challenge, especially given the fact that in all animal studies spironolactone was administered intracerebrally. Finally, the last animal study examining effects of MR blockade only found anxiolytic effects if spironolactone was administered $10 \mathrm{~min}$ before testing but did not find effect if it was administered $3 \mathrm{~h}$ before testing. In our study, participants received spironolactone 4 and $11 / 2 \mathrm{~h}$ before CCK was administered. Interestingly, a recent animal study examining transgenic mice with a specific limbic MR deficiency also failed to find anxiolytic effects in knockout $v s$ control animals (Berger et al, 2006).

Our results of increased baseline cortisol is consistent with earlier studies (Deuschle et al, 1998; Heuser et al, 2000a, b; Kellner et al, 2002a, b; Young et al, 1998) which have shown elevated basal plasma cortisol concentrations after administration of spironolactone. Also, after CRH stimulation (Arvat et al, 2001; Kellner et al, 2002a, b) as well as in a combined dexamethasone suppression/CRH stimulation test (Heuser et al, 2000a, b) and during exercise (Wellhoener et al, 2004) significant elevations of plasma cortisol after prior anti-MR treatment have been reported. Although in our study subjects started with much higher baseline cortisol levels during the spironolactone condition, the increase of ACTH was not different between conditions. One would expect the elevated cortisol to decrease the ACTH response to CCK but it did not. This might be explained by impaired negative feedback of ACTH after 
blockade of hippocampal MR which inhibit ACTH secretion (deKloet and Derijk, 2004).

Several limitations must be considered in our study. First, we only examined men to eliminate gender effects that are known to modulate experimentally induced panic, cognition, and HPA activity. Therefore, we do not know if our results are applicable to women as well. Although it is certainly important to examine gender effects with regard to MR blockade, we would have needed a sample size twice as large as ours to systematically do so. Given the results of this pilot study in men, future studies should systematically explore if there are gender effects regarding the consequences of MR blockade on anxiety and cognition. Even without gender effects, we had limited power to detect treatment differences in CCK-4 induced panic. However, the effect sizes for spironolactone treatment on the different measures of anxiety and arousal ranged from 0.01 to 0.15 indicating a negligible effect in men. As cortisol was increased after spironolactone, we cannot exclude that an increased activation of GR rather than blockade of $\mathrm{MR}$ might have contributed to our results. However, this seems unlikely as a recent meta-analysis examining the effects of exogenous cortisol administration on memory in humans found that studies in which cortisol was administered before learning and in the afternoon actually showed a memory enhancing effect of cortisol, that is, a memory enhancing effect of greater GR occupation (Het et al, 2005). Further, Lupien et al (2002) examined the effect of pharmacologically lowering cortisol levels leading to lower MR occupation in young healthy men and also found memory impairment. They and others (de Kloet et al, 1999; Lupien et al, 2005) hypothesized that MR activation is involved in behavioral reactivity in response to environmental clues consistent with our findings. Furthermore, there was no significant correlation between cortisol concentration after spironolactone and any of the neuropsychological tests in our study, which would be expected if cognitive impairment was related to increasing occupation of GR. Finally, spironolactone exerts some effects on androgen and progesterone receptors. This might have contributed to our results in addition of MR blockade.

In summary, we found that blockade of MR with spironolactone in healthy men impairs several aspects of cognition, particularly selective attention, visuospatial memory, and set shifting/mental flexibility but did not affect symptoms of panic, anxiety and arousal after a challenge with CCK-4.

\section{ACKNOWLEDGEMENTS}

We are grateful to the excellent technical assistance of Mrs Iris Remmlinger-Marten and Ms Kirsten Huwald. This study is part of the MD thesis of Ms Maike Koop and Ms Ana Maria Madrischewski. The study was supported by a grant from the Deutsche Forschungsgemeinschaft (DFG) to the first author (OT 209/4-1).

\section{REFERENCES}

Arvat E, Maccagno B, Giordano R, Pellegrino M, Broglio F, Gianotti L et al (2001). Mineralocorticoid receptor blockade by canrenoate increases both spontaneous and stimulated adrenal function in humans. J Clin Endocrinol Metab 86: 3176-3181.

Berger S, Wolfer DP, Selbach O, Alter H, Erdmann G, Reichardt $\mathrm{HM}$ et al (2006). Loss of the limbic mineralocorticoid receptor impairs behavioral plasticity. Proc Natl Acad Sci USA 103: 195-200.

Bitran D, Shiekh M, Dowd JA, Dugan MM, Renda P (1998). Corticosterone is permissive to the anxiolytic effect that results from the blockade of hippocampal mineralocorticoid receptors. Pharmacol Biochem Behav 60: 879-887.

Bradwejn J, Koszycki D, Paradis M, Reece P, Hinton J, Sedman A (1995). Effect of CI-988 on cholecystokinin tetrapeptide-induced panic symptoms in healthy volunteers. Biol Psychiatry 38: 742-746.

Brickenkamp $\mathrm{R}$ (1978). Test d2. Handanweisung [Test $d 2$. Manual]. Hogrefe: Göttingen (Germany).

Buckley T (2006). Hippocampal mineralocorticoid receptors in healthy aging and depression: overlapping cortisol circadian rhythm, sleep, and memory change. Depression: Mind and Body 2: 47-52.

Buckley TM, Schatzberg AF (2005). Aging and the role of the HPA axis and rhythm in sleep and memory-consolidation. Am J Geriatr Psychiatry 13: 344-352.

Conrad CD, Lupien SJ, Thanasoulis LC, McEwen BS (1997). The effects of type I and type II corticosteroid receptor agonists on exploratory behavior and spatial memory in the Y-maze. Brain Res 759: 76-83.

de Kloet ER, Joels M, Holsboer F (2005). Stress and the brain: from adaptation to disease. Nat Rev Neurosci 6: 463-475.

de Kloet ER, Oitzl MS, Joels M (1999). Stress and cognition: are corticosteroids good or bad guys? Trends Neurosci 22: 422-426.

deKloet E, Derijk R (2004). Signaling pathways in brain involved in predisposition and pathogenesis of stress-related disease: genetic and kinetic factors affecting the MR/GR balance. Ann NY Acad Sci 1032: 14-34.

Deuschle M, Weber B, Colla M, Muller M, Kniest A, Heuser I (1998). Mineralocorticoid receptor also modulates basal activity of hypothalamus-pituitary-adrenocortical system in humans. Neuroendocrinology 68: 355-360.

Dillon DJ, Gorman JM, Liebowitz MR, Fyer AJ, Klein DF (1987). Measurement of lactate-induced panic and anxiety. Psychiatry Res 20: 97-105.

Douma BR, Korte SM, Buwalda B, la Fleur SE, Bohus B, Luiten PG (1998). Repeated blockade of mineralocorticoid receptors, but not of glucocorticoid receptors impairs food rewarded spatial learning. Psychoneuroendocrinology 23: 33-44.

Gesing A, Bilang-Bleuel A, Droste SK, Linthorst AC, Holsboer F, Reul JM (2001). Psychological stress increases hippocampal mineralocorticoid receptor levels: involvement of corticotropinreleasing hormone. J Neurosci 21: 4822-4829.

Het S, Ramelow G, Wolf O (2005). A meta-analytic review of the effects of acute cortisol administration on human memory. Psychoneuroendocrinology 30: 771-784.

Heuser I, Deuschle M, Weber A, Kniest A, Ziegler C, Weber B et al (2000a). The role of mineralocorticoid receptors in the circadian activity of the human hypothalamus-pituitary-adrenal system: effect of age. Neurobiol Aging 21: 585-589.

Heuser I, Deuschle M, Weber B, Stalla GK, Holsboer F (2000b). Increased activity of the hypothalamus-pituitary-adrenal system after treatment with the mineralocorticoid receptor antagonist spironolactone. Psychoneuroendocrinology 25: 513-518.

Hiller W, Zaudig M, Mombour W, Bronisch T (1993). Routine psychiatric examinations guided by ICD-10 diagnostic checklists (International Diagnostic Checklists). Eur Arch Psychiatry Clin Neurosci 242: 218-223.

Holsboer F (2000). The corticosteroid receptor hypothesis of depression. Neuropsychopharmacology 23: 477-501. 
Jahn H, Schick M, Kiefer F, Kellner M, Yassouridis A, Wiedemann $\mathrm{K}$ (2004). Metyrapone as additive treatment in major depression: a double-blind and placebo-controlled trial. Arch Gen Psychiatry 61: $1235-1244$.

Kellner M, Baker DG, Yassouridis A, Bettinger S, Otte C, Naber D et al (2002a). Mineralocorticoid receptor function in patients with posttraumatic stress disorder. Am J Psychiatry 159: 1938-1940.

Kellner M, Yassouridis A, Hua Y, Wendrich M, Jahn H, Wiedemann K (2002b). Intravenous C-type natriuretic peptide augments behavioral and endocrine effects of cholecystokinin tetrapeptide in healthy men. J Psychiatr Res 36: 1-6.

Korte SM, de Boer SF, de Kloet ER, Bohus B (1995). Anxiolytic-like effects of selective mineralocorticoid and glucocorticoid antagonists on fear-enhanced behavior in the elevated plus-maze. Psychoneuroendocrinology 20: 385-394.

Ladd CO, Huot RL, Thrivikraman KV, Nemeroff CB, Plotsky PM (2004). Long-term adaptations in glucocorticoid receptor and mineralocorticoid receptor mRNA and negative feedback on the hypothalamo-pituitary-adrenal axis following neonatal maternal separation. Biol Psychiatry 55: 367-375.

Lezak MD (1995). Neuropsychological Assessment, Vol 3. edition. Oxford University Press: Oxford.

Lupien SJ, Fiocco A, Wan N, Maheu F, Lord C, Schramek T et al (2005). Stress hormones and human memory function across the lifespan. Psychoneuroendocrinology 30: 225-242.

Lupien SJ, Wilkinson CW, Briere S, Menard C, Ng Ying Kin NM, Nair NP (2002). The modulatory effects of corticosteroids on cognition: studies in young human populations. Psychoneuroendocrinology 27: 401-416.

Muller MB, Zimmermann S, Sillaber I, Hagemeyer TP, Deussing JM, Timpl P et al (2003). Limbic corticotropin-releasing hormone receptor 1 mediates anxiety-related behavior and hormonal adaptation to stress. Nat Neurosci 6: 1100-1107.

Oitzl MS, de Kloet ER (1992). Selective corticosteroid antagonists modulate specific aspects of spatial orientation learning. Behav Neurosci 106: 62-71.

Osterrieth PA (1944). Le test de copie d'une figure complexe; contribution a l'etude de la perception et de la memoire [Test of copying a complex figure; contribution to the study of perception and memory]. Archives de Psychologie 30: 206-356.

Otte C, Yassouridis A, Jahn H, Maass P, Stober N, Wiedemann K et al (2003). Mineralocorticoid receptor-mediated inhibition of the hypothalamic-pituitary-adrenal axis in aged humans. J Gerontol A Biol Sci Med Sci 58: B900-B905.

Pace TWW, Spencer RL (2005). Disruption of mineralocorticoid receptor function increases corticosterone responding to a mild, but not moderate, psychological stressor. Am J Physiol Endocrinol Metab 288: E1082-E1088.

Perez M, Godoy J (1998). Comparison between a 'traditional' memory test and a 'behavioral' memory battery in Spanish patients. J Clin Exp Neuropschol 20: 496-502.

Plihal W, Born J (1999). Memory consolidation in human sleep depends on inhibition of glucocorticoid release. Neuroreport 10: 2741-2747.

Rehfeld JF (2000). Cholecystokinin and panic disorder-three unsettled questions. Regul Pept 93: 79-83.
Reitan RM (1992). Trail Making Test. Manual of Administration and Scoring. Reitan Neuropsychology Laboratory: Tuscon, Arizona.

Rothuizen J, Reul JM, van Sluijs FJ, Mol JA, Rijnberk A, de Kloet ER (1993). Increased neuroendocrine reactivity and decreased brain mineralocorticoid receptor-binding capacity in aged dogs. Endocrinology 132: 161-168.

Sandi C, Rose SP (1994). Corticosteroid receptor antagonists are amnestic for passive avoidance learning in day-old chicks. Eur J Neurosci 6: 1292-1297.

Sandi C, Touyarotb K (2006). Mid-life stress and cognitive deficits during early aging in rats: individual differences and hippocampal correlates. Neurobiol Aging 27: 128-140.

Sheehan DV, Lecrubier Y, Sheehan KH, Amorim P, Janavs J, Weiller E et al (1998). The Mini-International Neuropsychiatric Interview (MINI): the development and validation of a structured diagnostic psychiatric interview for DSM-IV and ICD-10. J Clin Psychiatry 59: 22-33.

Smythe JW, Murphy D, Timothy C, Costall B (1997). Hippocampal mineralocorticoid, but not glucocorticoid, receptors modulate anxiety-like behavior in rats. Pharmacol Biochem Behav 56: 507-513.

Tewes U (1991). HAWIE-R: Hamburg-Wechsler Intelligenztest für Erwachsene; Handbuch und Testanweisung. Huber-Verlag: Bern.

Tytherleigh MY, Vedhara K, Lightman SL (2004). Mineralocorticoid and glucocorticoid receptors and their differential effects on memory performance in people with Addison's disease. Psychoneuroendocrinology 29: 712-723.

Wellhoener P, Born J, Fehm HL, Dodt C (2004). Elevated resting and exercise-induced cortisol levels after mineralocorticoid receptor blockade with canrenoate in healthy humans. J Clin Endocrinol Metab 89: 5048-5052.

Wiedemann K, Jahn H, Yassouridis A, Kellner M (2001). Anxiolyticlike effects of atrial natriuretic peptide on cholecystokinin tetrapeptide-induced panic attacks: preliminary findings. Arch Gen Psychiatry 58: 371-377.

Wilson B, Cockburn J, Baddeley A (1992). Rivermead Behavioural Memory Test. German translation. Thames Valley Test Company: Bury St. Edmunds (United Kingdom).

Yau JL, Hibberd C, Noble J, Seckl JR (2002). The effect of chronic fluoxetine treatment on brain corticosteroid receptor mRNA expression and spatial memory in young and aged rats. Brain Res Mol Brain Res 106: 117-123.

Yau JL, Noble J, Seckl JR (1999). Continuous blockade of brain mineralocorticoid receptors impairs spatial learning in rats. Neurosci Lett 277: 45-48.

Yau JL, Olsson T, Morris RG, Meaney MJ, Seckl JR (1995). Glucocorticoids, hippocampal corticosteroid receptor gene expression and antidepressant treatment: relationship with spatial learning in young and aged rats. Neuroscience 66: 571-581.

Young EA, Lopez JF, Murphy-Weinberg V, Watson SJ, Akil H (1998). The role of mineralocorticoid receptors in hypothalamicpituitary-adrenal axis regulation in humans. J Clin Endocrinol Metab 83: 3339-3345.

Young EA, Lopez JF, Murphy-Weinberg V, Watson SJ, Akil H (2003). Mineralocorticoid receptor function in major depression. Arch Gen Psychiatry 60: 24-28. 